\title{
Formation of Lymph Follicles and Germinal Centers in Draining Lymph Nodes after Local Injection of Phytohemagglutinin and Lipopolysaccharide in Mice
}

\author{
Hajime Hoshi, Kaeko KamiYa, Ritsuko Takemoto and Hiroshi Aijima \\ Department of Anatomy (Prof. H. Hoshi), Nihon University School of Medicine, Tokyo, Japan
}

Received March 14, 1984

\begin{abstract}
Summary. Changes in the number of lymph follicles and germinal centers in draining popliteal lymph nodes were investigated in 8-week-old mice injected with either phytohemagglutinin (PHA) or lipopolysaccharide (LPS) into the footpad of the left hind leg. The dose of PHA injected ranged from $10 \mu \mathrm{g}$ to $1 \mathrm{mg}$, and that of LPS, from 2 to $200 \mu \mathrm{g}$. In unstimulated animals, the popliteal lymph nodes contained only a small number of germinal centers, and many of the lymph follicles in the nodes were in the form of primary follicles. In the draining lymph nodes, regardless of the dose injected, PHA induced germinal center development in existing primary follicles, but eventually failed to stimulate the formation of new lymph follicles and germinal centers. On the other hand, LPS not only induced germinal centers in the existing follicles, but also stimulated the formation of new primary follicles, many of which then developed germinal centers. The occurrence of new follicles in the LPS-treated lymph nodes was dose-dependent, and LPS appeared to cause de novo formation of follicles.
\end{abstract}

Although there is general agreement that germinal center development in the lymphoid organs is a histological response to antigens, the formation of the lymph follicle and of the germinal center and the developmental relationships between these two structures are not yet clearly understood. Maximow (1927) and Bloom (1938) considered that the primary follicles formed in some way in the lymphoid organ in the course of the organ's development and that the germinal centers developed secondarily in the primary follicles and underwent cyclic changes. The importance of pre-existing primary follicles as sites for germinal center development was emphasized by Nossal et al. $(1964,1971)$ in their work on the distribution of injected antigens in the lymphoid organs. On the other hand, it has frequently been reported that after antigenic stimuli, new secondary follicles develop in the lymphoid organs independently of pre-existing follicles (e.g., Sjövall and Sjövall, 1930; Rudebeck, 1932; Conway, 1937; Yoffey and Olson, 1967; ONoÉ, 1976). In her study on changes induced by B. monocytogenes, Conway (1937) observed that "bare germinal centers" arose in the lymph nodes and spleen within 36 hrs after the stimuli, and proposed that these centers represented an initial structure prior to the formation of new secondary follicles. While her views have received considerably wide acceptance, the observations presented by Conway have been criticized by SAINTE-MARIE and Sin (1970), who maintained that such rapid formation of new germinal centers following antigenic stimulation was inconceivable because the formation of new germinal centers would require considerable reorganization of the local 
pattern of reticular fibers and blood vessels. In view of these contradictory opinions, the present study was undertaken in an attempt to re-examine the formation of new lymph follicles and new germinal centers in the lymph nodes following antigenic stimuli.

In the course of investigating the induction of lymph follicles and germinal centers in the lymph nodes by various antigenic and mitogenic substances, we have become convinced that some substances have the ability to stimulate the formation of new secondary follicles, while others do not, even though they can induce germinal centers in the primary follicles. Phytohemagglutinin (PHA) is included in the latter category and bacterial lipopolysaccharide (LPS) in the former.

The present report describes changes in the number of lymph follicles and germinal centers as well as the histological changes in the draining popliteal lymph nodes of the mouse at various intervals after footpad injection of different doses of PHA and LPS.

\section{MATERIALS AND METHODS}

Animals and injection of stimulants: Male C57B1/6 mice, at 8 weeks of age, were used in this study. They were allowed free access to food and water.

Phytohemagglutinin P (PHA; Difco), and Boivin preparation of lipopolysaccharide (LPS; E. Coli lipopolysaccharide B, lot 0111, B4, Difco) were freshly dissolved in sterile physiological saline before use. Fifty $\mu$ l of PHA or LPS solution was injected into the footpad of the left hind leg. The animals were divided into eight groups. Four groups received PHA at a dose of $10,50,200 \mu \mathrm{g}$ or $1 \mathrm{mg}$, while the other four groups were given $2,10,50$ or $200 \mu \mathrm{g}$ of LPS, respectively.

The animals were sacrificed at various intervals after the injection. In each group, at least three mice were sacrificed at each stage.

Tissue processing: At autopsy, the popliteal nodes from both sides were removed, cleared from the surrounding fat and weighed. The popliteal nodes of the right hind leg were used as a control. Popliteal nodes were also obtained from unstimulated mice and served as an additional control.

The specimens were fixed in Zenker-formol solutions or buffered $10 \%$ formalin, dehydrated and embedded using a JB-4 kit. Serial sections of the Zenker-formol-fixed material, cut at $3 \mu \mathrm{m}$, were prepared and stained with May-Grünwald and Giemsa stains. Two series of serial sections were prepared from the formalin-fixed material. One series was impregnated with silver according to a modification of Bielschowsky's technique, while the other series was stained with May-Grünwald and Giemsa solutions.

Three-dimensional analysis and morphometric studies: Each nodal section was examined under a light microscope in order to verify the presence of lymph follicles and germinal centers. Each follicle or germinal center encountered in the section was identified with a reference number and was traced three-dimensionally in subsequent sections. The reconstruction technique permitted us to determine the total number of lymph follicles and germinal centers in each node.

Morphometric studies were carried out on the lymph nodes obtained from animals treated with LPS. Each lymph follicle in a section, identified as described above, was outlined under a light microscope at $\times 100$ magnification and its size was measured to the order of $10^{-5} \mathrm{~mm}^{2}$, utilizing an image analyzer (Digiplan, Kontron, München). The follicle was traced in subsequent sections and its size was measured in each section. By employing this procedure, the largest size of a given follicle was determined as the size of the follicles. 
Demonstration of surface immunoglobulin of $B$ lymphocytes in tissue sections: The animals injected with LPS at a dose of 50 or $200 \mu \mathrm{g}$, were sacrificed at 5, 9 and 21 days after the injection. The popliteal lymph node on the injected side and the liver were removed. The lymph node was inserted into a slit in a small block of the liver and rapidly frozen, using a dry ice-acetone mixture.

The cell surface immunoglobulin was detected by the indirect immunohistochemical method in $6 \mu \mathrm{m}$ frozen sections, fixed for $30 \mathrm{~min}$ in acetone. Peroxidase staining was carried out as follows: $1 \mathrm{hr}$ incubation at $37^{\circ} \mathrm{C}$ with rabbit anti-mouse IgM-serum (Fujizoki Chemical: diluted 1:10), 5 min washing in PBS, 30 min incubation with peroxidase-conjugated anti-globulin serum (Fujizoki Chemical; goat anti-rabbit IgG, diluted 1:10), 5 min washing in PBS, and 5 to 20 min reaction with diaminobenzidine and $\mathrm{H}_{2} \mathrm{O}_{2}$.

\section{RESULTS}

As the normal structure of the mouse popliteal lymph node has been described previously (HosHi et al., 1981), the present paper will give only a brief description of certain aspects of the lymph node in 8-week-old, male C57B1/6 mice. The total number of detectable lymph follicles per popliteal node usually ranged from 9 to 13 , and only a small number of follicles contained germinal centers. In sections stained with MayGrünwald and Giemsa solutions, the lymph follicles were readily distinguishable from the surrounding extrafollicular zone, being much denser in cellularity (Fig. 2, 6). In silver-impregnated sections, they were observed as round or ovoid structures with relatively sparse argyrophil fibers (Fig. 3). The size of the lymph follicles, as measured from the largest cross-sectional area, ranged from 0.01 to $0.10 \mathrm{~mm}^{2}$ (Table 3). Most of the follicles were located in the superficial cortex overlying the deep cortex. A thin band of parenchyma was noted under the subcapsular sinus, extending from the lateral margin of the mass of the cortex to the hilar region. This band was marked off from the superficial cortex by a paucity of lymphocytes and rare occurrence of lymph follicles under normal conditions. For convenience of description, this band will be referred to as the parenchymal band.

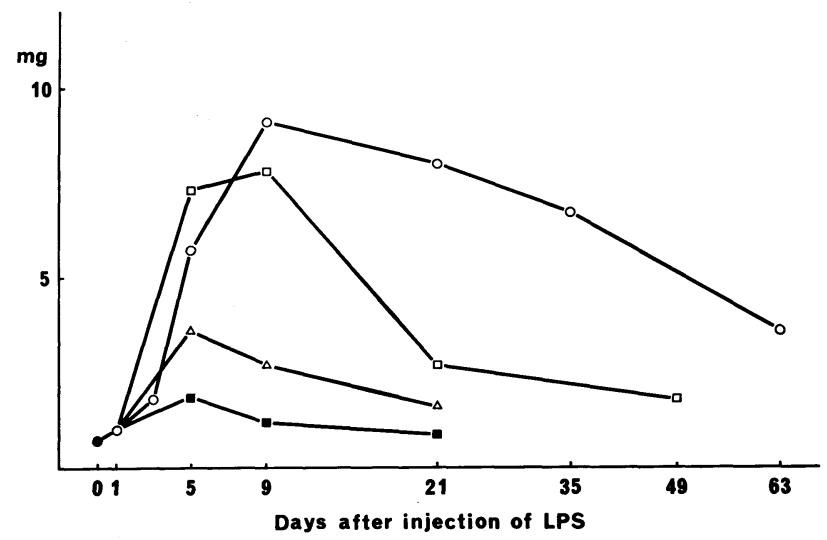

Fig. 1. Weight of popliteal lymph nodes on the injected side at various intervals after injection of LPS. $2-\mu \mathrm{g}$ dose, $\triangle \longrightarrow \triangle: 10-\mu \mathrm{g}$ dose, $\square \longrightarrow$ - $\square$ $\mu \mathrm{g}$ dose, $\bigcirc \longrightarrow: 200-\mu \mathrm{g}$ dose, $\bigcirc$ : before injection. Each point represents the mean wet weight of lymph nodes obtained from three mice. 


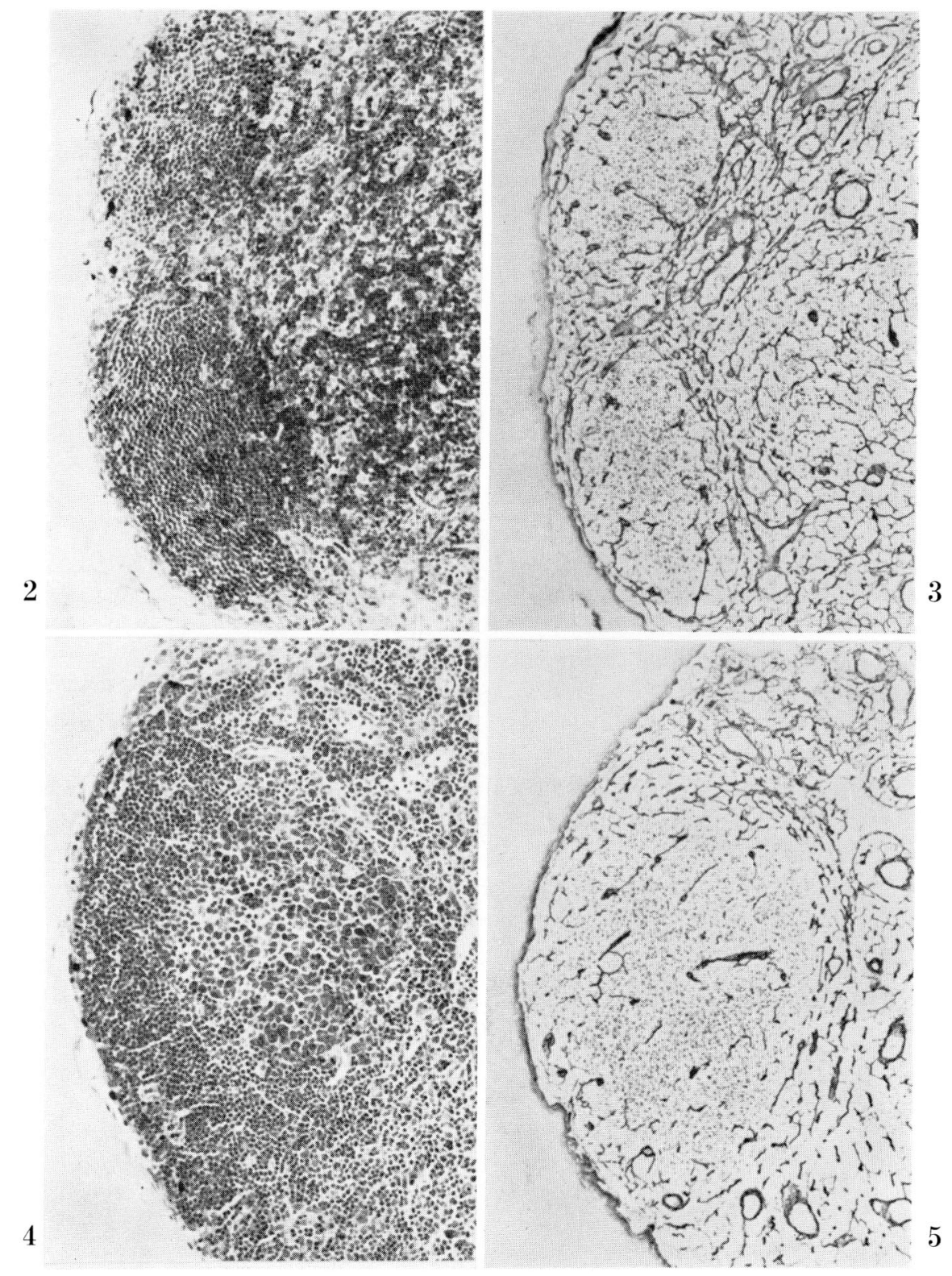

Fig. 2. Portion of a popliteal lymph node obtained from an untreated mouse showing two primary follicles in the superficial cortex. $\quad \times 140$

Fig. 3. Silver-impregnated section obtained from the same material as in Figure 2. Two lymph follicles containing sparse argyrophil fibers are seen. $\quad \times 140$

Fig. 4. Portion of a popliteal lymph node on the injected side at 9 days after injection of $50 \mu \mathrm{g}$ of PHA. A secondary follicle is enlarged and contains a prominent germinal center in its medullary pole. $\times 140$

Fig. 5. Silver-impregnated section of a popliteal node on the injected side at 9 days after injection of $50 \mu \mathrm{g}$ of PHA, showing an enlarged follicle containing sparse argyrophil fibers. $\times 140$ 
Table 1. Number of lymph follicles per whole popliteal node at different intervals after injection of PHA into the footpad

\begin{tabular}{|c|c|c|c|c|}
\hline Dose and interval & $\begin{array}{l}\text { Number of follicl } \\
\text { on the untreated }\end{array}$ & $\begin{array}{l}\text { les per node } \\
\text { side }\end{array}$ & $\begin{array}{l}\text { Number of folli } \\
\text { on the injected }\end{array}$ & $\begin{array}{l}\text { les per node } \\
\text { ide }\end{array}$ \\
\hline Untreated control & 11. $7 \pm 1.2^{2)}$ & $(3.7)^{3)}$ & 11. $0 \pm 1.7$ & $(4.0)$ \\
\hline $\begin{array}{c}10 \mu \mathrm{g} \text { of PHA } \\
5 \text { d. }{ }^{1} \\
9 \text { d. } \\
21 \mathrm{~d} .\end{array}$ & $\begin{array}{l}12.3 \pm 1.2 \\
10.7 \pm 1.5 \\
10.4 \pm 1.1\end{array}$ & $\begin{array}{l}(0.3) \\
(4.7) \\
(2.8)\end{array}$ & $\begin{array}{l}\text { 12. } 0 \pm 2.6 \\
11.0 \pm 2.0 \\
11.2 \pm 2.2\end{array}$ & $\begin{array}{l}(0) \\
(* \# 9.7) \\
(* 10.0)\end{array}$ \\
\hline $\begin{array}{c}50 \mu \mathrm{g} \text { of PHA } \\
5 \mathrm{~d} . \\
9 \mathrm{~d} . \\
21 \mathrm{~d} .\end{array}$ & $\begin{array}{l}11.0 \pm 1.0 \\
10.3 \pm 2.1 \\
10.5 \pm 0.6\end{array}$ & $\begin{array}{l}(1.0) \\
(2.3) \\
(4.0)\end{array}$ & $\begin{array}{l}11.3 \pm 1.5 \\
11.0 \pm 1.0 \\
10.5 \pm 3.5\end{array}$ & $\begin{array}{l}(5.3) \\
(* \# 10.7) \\
(10.0)\end{array}$ \\
\hline $\begin{array}{c}200 \mu \mathrm{g} \text { of PHA } \\
5 \mathrm{~d} . \\
9 \mathrm{~d} . \\
21 \mathrm{~d} .\end{array}$ & $\begin{array}{l}11.3 \pm 0.6 \\
10.3 \pm 1.5 \\
10.0 \pm 0\end{array}$ & $\begin{array}{l}(0 \quad) \\
(3.3) \\
(4.7)\end{array}$ & $\begin{array}{l}11.0 \pm 1.0 \\
12.0 \pm 1.0 \\
10.3 \pm 0.6\end{array}$ & $\begin{array}{l}(3.3) \\
(* \# 12.0) \\
(* \# 10.3)\end{array}$ \\
\hline $\begin{array}{c}1 \mathrm{mg} \text { of PHA } \\
4 \mathrm{~d} . \\
6 \mathrm{~d} . \\
9 \mathrm{~d} . \\
21 \mathrm{~d} .\end{array}$ & $\begin{array}{l}11.5 \pm 0.6 \\
10.3 \pm 1.3 \\
10.8 \pm 1.7 \\
10.7 \pm 1.5\end{array}$ & $\begin{array}{l}(1.5) \\
(4.0) \\
(4.5) \\
(2.3)\end{array}$ & $\begin{array}{l}13.3 \pm 1.7 \\
14.0 \pm 0.8 \\
12.5 \pm 1.0 \\
14.3 \pm 0.6\end{array}$ & $\begin{array}{l}(0) \\
(10.3) \\
(* \# 10.5) \\
(* \# 12.0)\end{array}$ \\
\hline
\end{tabular}

1) Three animals were examined.

2) Mean \pm SD.

3) The number in parentheses indicates the mean number of secondary follicles per node.

* The number of the node on the injected side was significantly different $(p<0.05: t$ test) from that of the node on the contralateral side.

\# The number of the node on the injected side was significantly different ( $<<0.05: t$ test) from that of the untreated control node.

\section{Popliteal lymph nodes after PHA}

Animals were sacrificed at days 4 to 6,9 and 21 after injection of PHA. After the injection, the draining popliteal nodes revealed a slight and dose-dependent increase in weight, but the weight had returned to near normal by 21 days after the injection.

There was no significant difference in histology between the lymph nodes following treatment with PHA at doses of 10,50 and $200 \mu \mathrm{g}$. On day 5, the cortex was enlarged. Germinal centers were found in many of the lymph follicles. They were seen as aggregations of basophilic blast cells in the medullary pole of such secondary follicles. On days 9 and 21, almost all the lymph follicles in the draining nodes contained prominent germinal centers which occupied a central position in the medullary pole of the follicles (Fig. 4, 5). The total number of detectable lymph follicles including secondary follicles in the treated nodes was comparable to that in the popliteal nodes of untreated animals (Table 1).

There was a very slight increase in the number of lymph follicles in the popliteal lymph nodes given a $1 \mathrm{mg}$ injection of PHA (Table 1). The increase was first noticed on day 4 , and remained at days 9 and 21 . In these treated nodes, many of the lymph follicles were large and contained germinal centers, although some were small and devoid of germinal centers.

\section{Politeal lymph nodes after LPS}

Animals were killed at various intervals from 1 day to 9 weeks after the injection. The dates of sacrifice are indicated in Table 2. 
Table 2. Number of lymph follicles per whole popliteal node at different intervals after injection of LPS into the footpad

\begin{tabular}{|c|c|c|c|c|}
\hline Dose and interval & $\begin{array}{l}\text { Number of follic } \\
\text { on the untreated }\end{array}$ & $\begin{array}{l}\text { cles per node } \\
\text { d side }\end{array}$ & $\begin{array}{l}\text { Number of folli } \\
\text { on the injected }\end{array}$ & $\begin{array}{l}\text { cles per node } \\
\text { side }\end{array}$ \\
\hline Untreated control & 11. $3 \pm 1.2^{2)}$ & $(0.3)^{3)}$ & $12.0 \pm 1.4$ & (0) \\
\hline $\begin{aligned} 2 \mu \mathrm{g} \text { of } \mathrm{LPS} \\
\left.5 \mathrm{~d}{ }^{1}\right) \\
9 \mathrm{~d} . \\
21 \mathrm{~d} .\end{aligned}$ & $\begin{array}{l}\text { 12. } 3 \pm 1.2 \\
11.8 \pm 2.8 \\
12.0 \pm 1.7\end{array}$ & $\begin{array}{l}(0.7) \\
(1.8) \\
(0.7)\end{array}$ & $\begin{array}{l}\text { 12. } 7 \pm 2.3 \\
11.8+2.2 \\
13.3 \pm 1.5\end{array}$ & $\begin{array}{l}(* \# 10.7) \\
(* \# 11.0) \\
(* \# 12.0)\end{array}$ \\
\hline $\begin{array}{c}10 \mu g \text { of LPS } \\
1 \mathrm{~d} . \\
5 \mathrm{~d} . \\
9 \mathrm{~d} . \\
21 \mathrm{~d} .\end{array}$ & $\begin{array}{l}11.0 \pm 0.8 \\
10.3 \pm 0.9 \\
14.3 \pm 1.7 \\
10.7 \pm 0.9\end{array}$ & $\begin{array}{l}(0) \\
(1.7) \\
(4.0) \\
(3.0)\end{array}$ & $\begin{array}{r}11.7 \pm 0.9 \\
14.7 \pm 1.7 \\
\# 15.0 \pm 0.8 \\
17.3 \pm 2.5\end{array}$ & $\begin{array}{l}(0) \\
(* \# 11.7) \\
(\# 14.3) \\
(* 16.0)\end{array}$ \\
\hline $\begin{array}{c}50 \mu \mathrm{g} \text { of LPS } \\
1 \mathrm{~d} . \\
5 \mathrm{~d} . \\
9 \mathrm{~d} . \\
21 \mathrm{~d} . \\
49 \mathrm{~d} .\end{array}$ & $\begin{array}{l}11.3 \pm 0.5 \\
11.0 \pm 1.6 \\
12.3 \pm 0.9 \\
11.7 \pm 4.2 \\
11.7 \pm 0.6\end{array}$ & $\begin{array}{l}(0.3) \\
(3.7) \\
(3.0) \\
(2.7) \\
(3.0)\end{array}$ & $\begin{array}{r}9.8 \pm 0.9 \\
* \# 18.3 \pm 0.5 \\
* \# 33.0 \pm 6.1 \\
\# 23.3 \pm 5.1 \\
18.0 \pm 4.0\end{array}$ & $\begin{array}{l}(0) \\
(\# 9.7) \\
(* \# 30.0) \\
(* \# 22.0) \\
(* \# 14.7)\end{array}$ \\
\hline $\begin{aligned} & 200 \mu \mathrm{g} \text { of LPS } \\
& 1 \mathrm{~d} . \\
& 3 \mathrm{~d} . \\
& 5 \mathrm{~d} . \\
& 9 \mathrm{~d} . \\
& 21 \mathrm{~d} . \\
& 35 \mathrm{~d} . \\
& 63 \mathrm{~d} .\end{aligned}$ & $\begin{array}{r}11.3 \pm 2.0 \\
9.8 \pm 1.2 \\
11.7 \pm 1.2 \\
10.3 \pm 1.7 \\
10.0 \pm 2.0 \\
10.7 \pm 2.1 \\
11.3 \pm 1.5\end{array}$ & $\begin{array}{l}(0.7) \\
(0.7) \\
(2.0) \\
(4.3) \\
(3.3) \\
(3.3) \\
(3.3)\end{array}$ & $\begin{array}{r}10.7 \pm 1.7 \\
12.0 \pm 2.0 \\
14.3 \pm 3.3 \\
* \# 20.0 \pm 1.2 \\
* \# 34.3 \pm 6.0 \\
* \# 31.3 \pm 7.5 \\
* \# 30.0 \pm 9.5\end{array}$ & $\begin{array}{c}(0) \\
(0) \\
(0) \\
(* \# 16.7) \\
(* \sharp 23.7) \\
(* \# 27.0) \\
(* \sharp 25.7)\end{array}$ \\
\hline
\end{tabular}

1) Three animals were examined.

2) Mean \pm SD.

3) The number in parentheses indicates the mean number of secondary follicles per node.

* The number of the node on the injected side was significantly different ( $<<0.05: t$ test) from that of the node on the contralateral side.

\# The number of the node on the injected side was significantly different $(\mathrm{p}<0.05: \mathrm{t}$ test) from that of the untreated control node.

Figure 1 shows the weight of draining popliteal lymph nodes after the injection of different doses of LPS. The change in weight was apparently related to the morphological changes.

After injection of $2 \mu \mathrm{g}$ of LPS, germinal centers developed in the lymph follicles of the draining lymph nodes. When examined at days 9 and 21 , almost all the follicles contained prominent germinal centers, but the total number of detectable lymph follicles including these secondary follicles per node remained at the normal level (Table 2).

After higher doses, there was an increase in the number of detectable lymph follicles and germinal centers in the treated lymph nodes, and the increase was dosedependent (Table 2). At $24 \mathrm{hrs}$, no germinal centers were found in the follicles. At 5 days, both the cortex and medulla were enlarged. The lymph follicles had expanded, and germinal centers were noted in the medullary pole of the follicles (Fig. 7). Blast cells were scattered among small lymphocytes in the cap region of the follicles. In addition, smaller lymph follicles consisting mostly of small lymphocytes were observed in the superficial cortex between the expanded follicles and in the parenchymal band (Fig. 7, 9-11). The expanded follicles were larger than $0.10 \mathrm{~mm}^{2}$, and the number of expanded follicles in the whole treated node was roughly comparable to the total num- 
Table 3. Size distribution of lymph follicles in the popliteal lymph node on the injected side at different intervals after injection of LPS into the footpad

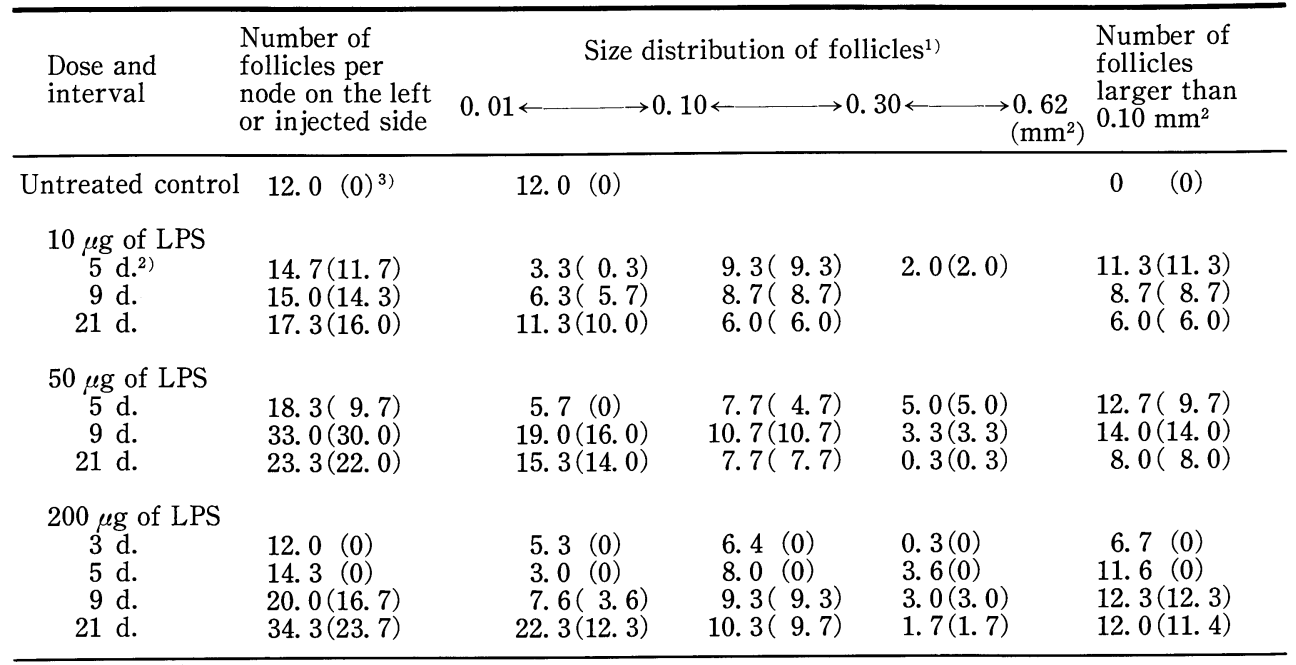

1) The size of each follicle is represented by the largest size as determined in serial sections.

2) Three lymph nodes were examined.

3) The number in parentheses indicates the number of follicles which contained germinal centers.

ber of follicles found in the popliteal nodes of untreated animals (Table 3). The expanded follicles thus corresponded to those which had been present in a detectable form in the lymph node before the treatment, whereas the smaller follicles represented newly developed follicles. New primary follicles usually appeared at some distance from the expanded follicles, although they were also observed in close proximity. In the latter case, the extrafollicular tissue containing high-endothelial postcapillary venules, even though narrow, tended to separate the two structures. Occasional lymphocytic nodules resembling small primary follicles were also found in the medullary cord and cortico-medullary junction, but they were not included in the count of follicles.

At 9 days, the expanded follicles were still large and contained prominent germinal centers. Newly developing follicles in the superficial cortex and parenchymal band were increased in size and number. Many of the new follicles had developed germinal centers in the basal portion (Fig. 12). By 21 days, the expanded follicles were diminished in size while newly developed ones were enlarged, so that it was impossible to distinguish the former from the latter (Fig. 8). From this time on, the lymph follicles per node tended to decrease in number.

At 5 and 9 days, plasma cells were numerous in the medullary cord and the parenchymal band, but by 21 days they had markedly diminished in number in the treated nodes.

\section{Lymph follicles as aggregations of lymphocytes bearing surface immunoglobulin}

Immunohistochemistry clearly demonstrated the distribution of B lymphocytes bearing surface IgM. The lymph follicles of the mouse lymph node appeared as aggregations of IgM-bearing lymphocytes (HosHI et al., 1981). In sections of the untreated popliteal lymph node, two or three lymph follicles were noted, each consisting largely of IgMbearing lymphocytes (Fig. 13). 
6
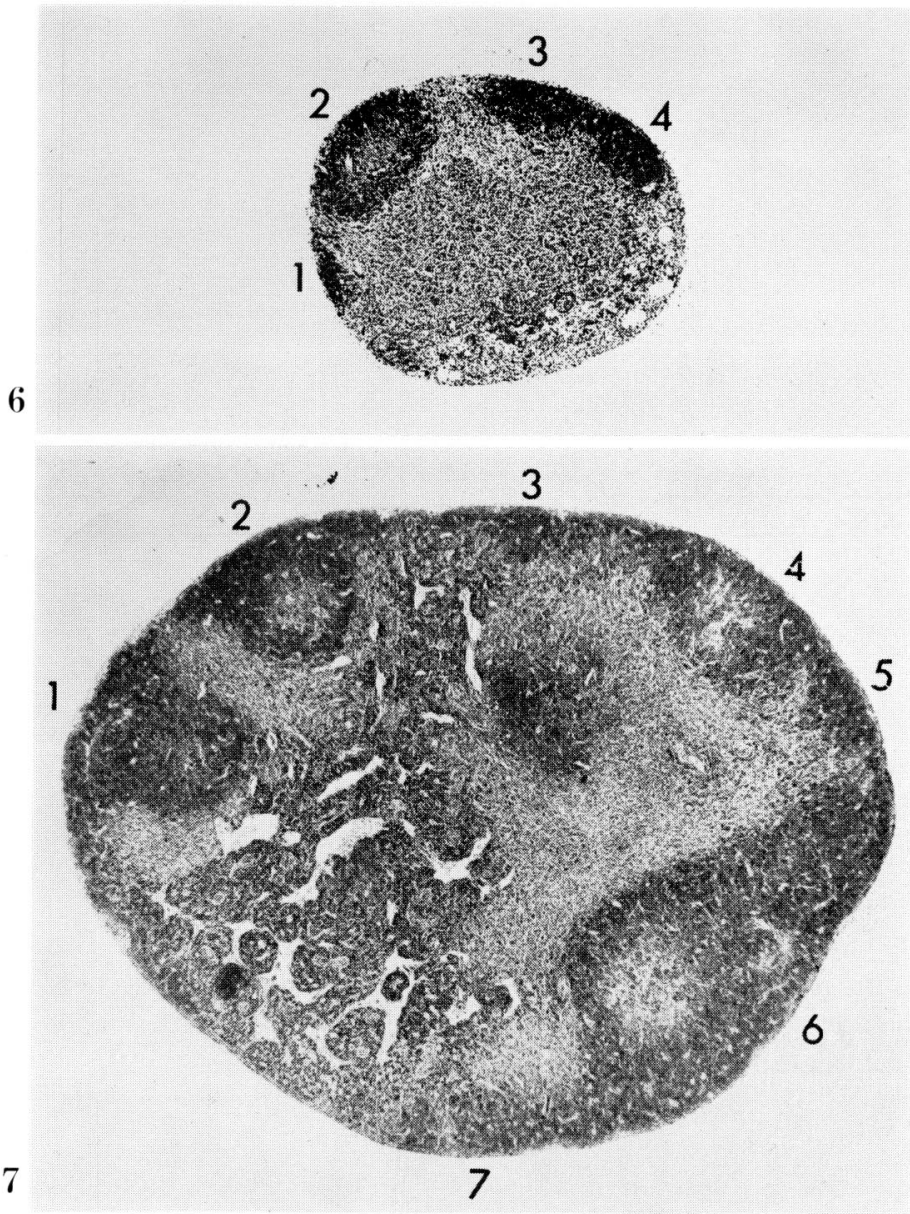

Fig. 6-8. Sections of the middle of popliteal lymph nodes on the injected side.

Fig. 6. Untreated control node. Four lymph follicles are seen in the superficial cortex of the node. Follicle 1 displays only part of the structure. $\times 35$
Fig. 7. A popliteal node at 5 days after injection of $50 \mathrm{\mu g}$ of LPS. Seven lymph follicles are seen in the periphery of the node. Follicles 1,2, 4 and 6 are expanded and contain germinal centers, whereas follicles 3, 5 and 7 are small and devoid of germinal centers. Follicle 3 is shown at a higher magnification in Figure 10. $\times 30$

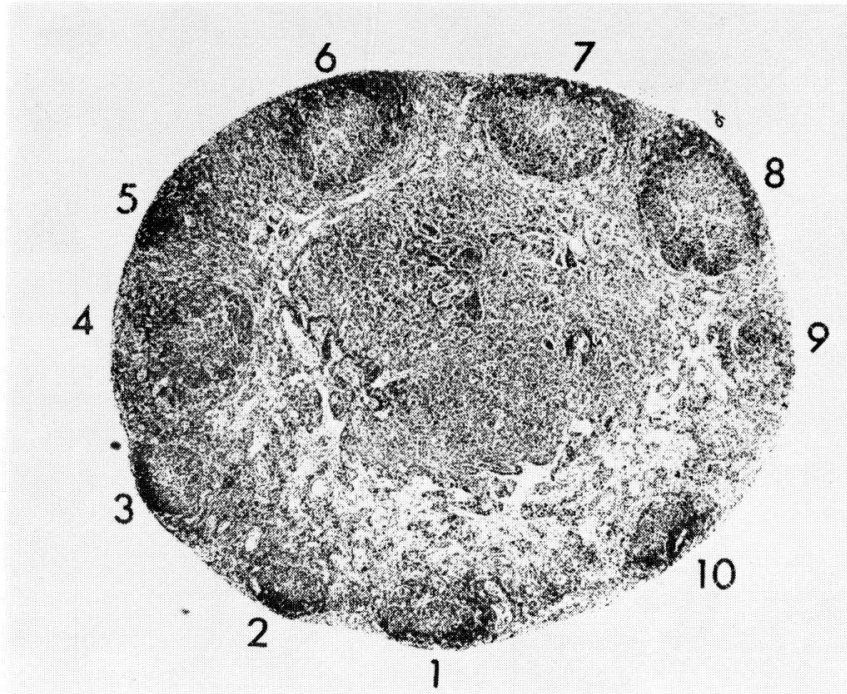

Fig. 8. A popliteal node at 21 days after injection of 50 $\mu \mathrm{g}$ of LPS. Examination of serial sections demonstrated that all ten follicles shown in this figure contained germinal centers. $\times 35$ 


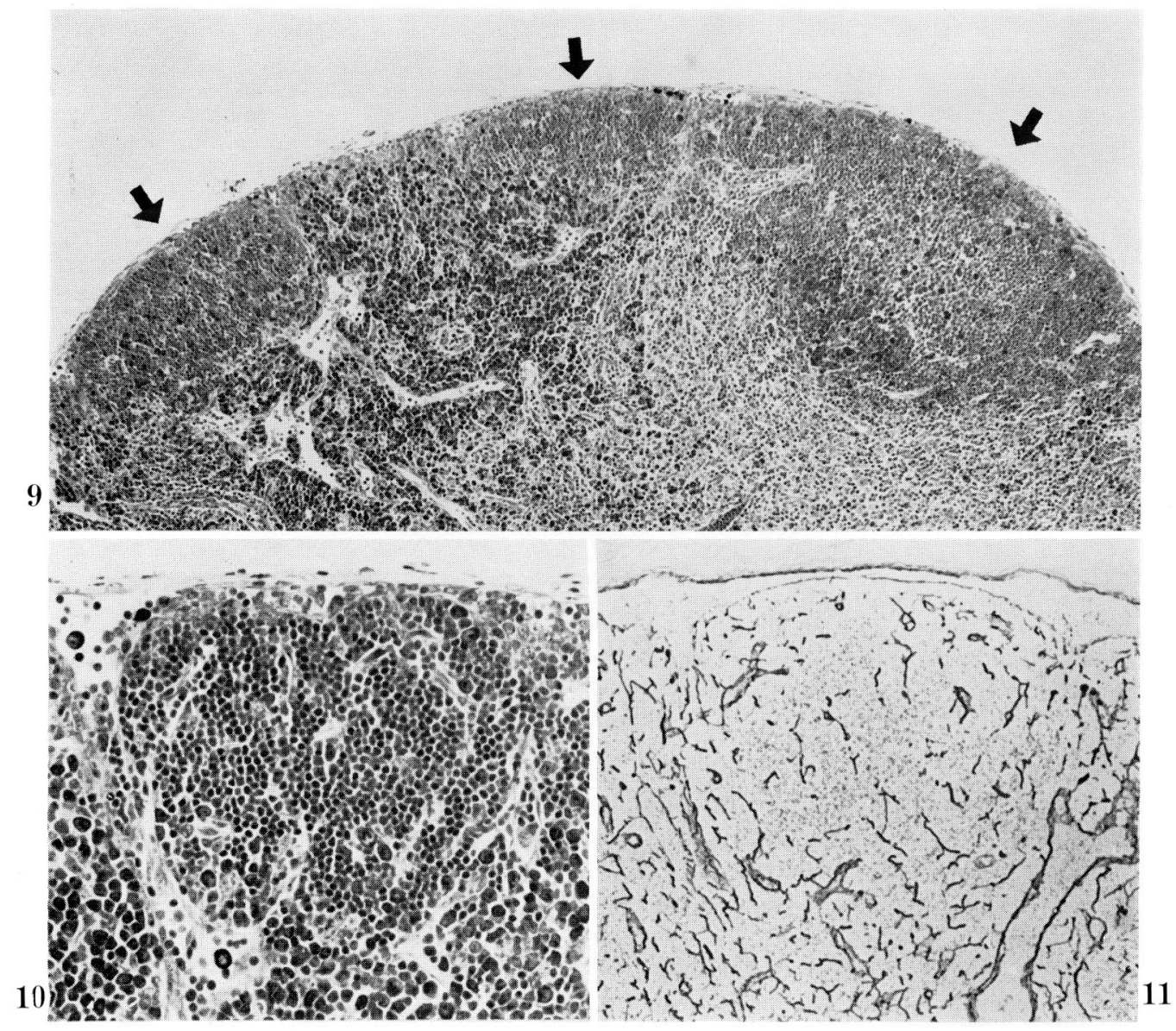

Fig. 9-11. Popliteal nodes on the injected side at 5 days after injection of $50 \mu \mathrm{g}$ of LPS.

Fig. 9. Three lymph follicles (arrow) are seen in the peripheral cortex. The lymph follicle on the right is fairly large and contains a germinal center, while the two other follicles are rather small and devoid of germinal centers. $\times 100$

Fig. 10. A developing primary follicle occurring in the peripheral cortex. This follicle corresponds to follicle 3 in Figure $7 . \times 220$

Fig. 11. Portion of a silver-impregnated section showing a small follicle containing sparse argyrophil fibers. $\times 180$

In the lymph nodes at 5 days after LPS treatment, the $1 y$ mph follicles were apparently enlarged, as illustrated in Figure 14. At this stage, three or four enlarged follicles were commonly observed in sections cut through the middle of the treated nodes. Figure 15 shows a lymph node obtained at 21 days after a $50 \mu \mathrm{g}$ dose of LPS. In this figure, seven lymph follicles are discernible, the number of follicles per section being clearly larger than that in the popliteal node of untreated animals. The results of this series of observations confirm the above description for the changes in size and number of lymph follicles in the lymph node occurring after LPS treatment. 


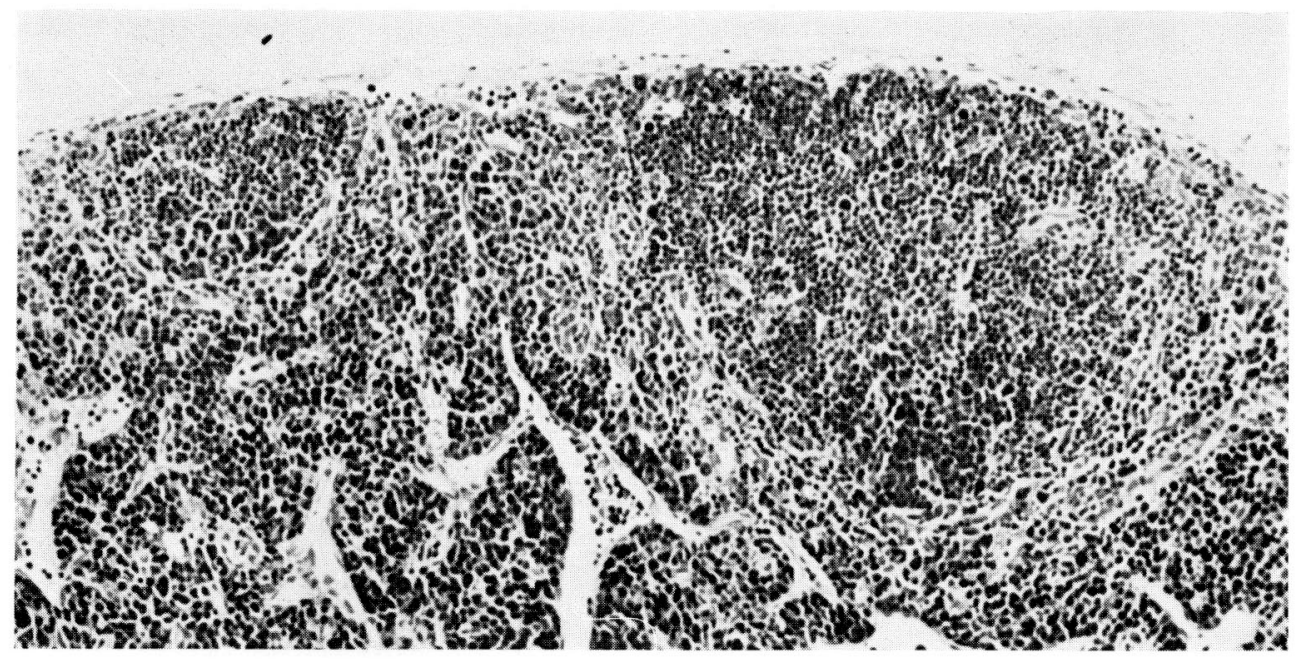

Fig. 12. Portion of a popliteal lymph node on the injected side at 9 days after a $50-\mu$ dose. Two lymph follicles are seen in the peripheral band. The follicle on the right is moderately large and contains a germinal center. The follicle on the left, although small, also contains a germinal center in its basal portion. Note that numerous plasma cells populate the medullary cord and the parenchyma between the follicles. $\times 150$

\section{DISCUSSION}

In the untreated C57B1/6 mice used in this study, the popliteal lymph nodes were found to contain a fairly constant number of detectable lymph follicles, many of which were in the form of primary follicles. It has been claimed that under unstimulated conditions, lymph follicles with resting germinal centers in the lymph node are sometimes very difficult to distinguish from the extrafollicular zone in sections stained by standard techniques (SAinte-Marie and Sin, 1970). Such undetectable follicles are said to be reactivated rapidly by antigenic stimuli and to become readily detectable once again, taking the form of typical secondary follicles. The possibility existed, therefore, that the popliteal lymph nodes in the untreated mice contained, in addition to detectable lymph follicles, a certain number of underdeveloped lymph follicles which we failed to detect. We must first consider this possibility.

After footpad injection of different doses of PHA, germinal centers developed in almost every lymph follicle. The number of lymph follicles per whole popliteal node eventually remained almost the same as that of detectable follicles found in the popliteal nodes of untreated animals, regardless of the dose injected. PHA possesses antigenicity (Byrd et al., 1964; Marshall and Melman, 1966). As an antigen, PHA may be trapped by the follicular dendritic cells in the primary follicles that were already present in a detectable form in the node before treatment, and thereby the trapped antigen may stimulate germinal center development in the follicles (Mitchell and Аввот, 1965; Nossal et al., 1968; Klaus et al., 1980). Our unpublished observations have also shown that antigens, such as diphtheria toxoid and human gamma globulin, induced germinal center development in the lymph follicles with no recognizable change in the total number of detectable lymph follicles per node. It seems likely therefore that the popliteal lymph node in unstimulated mice contains few, if any, underdeveloped lymph follicles other than the follicles which are detectable by means of standard histological techniques. 


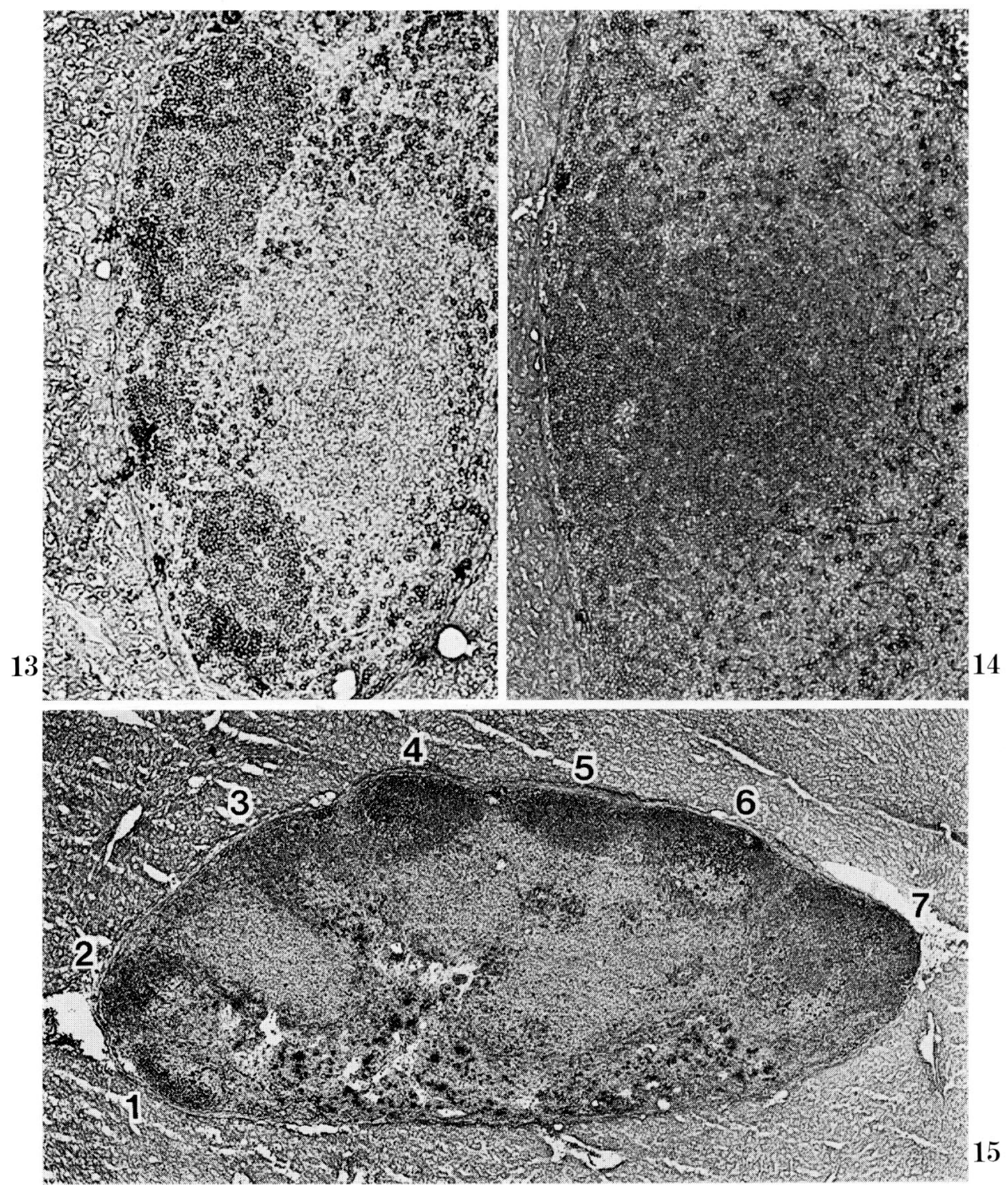

Fig. 13-15. Demonstration of lymphocytes bearing surface IgM in frozen sections by the immunohistochemical method.

Fig. 13. Untreated popliteal node. Two aggregations of IgM-bearing lymphocytes, each representing a lymph follicle, are seen in the periphery of the lymph node, which is surrounded by liver tissue. $\times 140$

Fig. 14. A popliteal node at 5 days after a $50-\mu \mathrm{g}$ dose of LPS, showing a follicle in the form of an aggregation of IgM-bearing lymphocytes. The follicle is apparently enlarged compared to those in Figure $13 . \times 140$

Fig. 15. A popliteal node at 21 days after a 50the periphery of the node. Follicles 1,2 and 6 contain a germinal center which is recognizable as a faintly stained area in the basal portion. Follicle 3 displays only part of the structure. $\times 50$ 
LPS is known to be an effective inducer of germinal centers in lymphoid organs (ONOÉ, 1976; WeIsSman et al., 1976). In the present experiments, the draining lymph nodes showed an increased number of germinal centers per node, regardless of the LPS dose. At lower doses, the increase was attributable to germinal center development in the primary follicles which had existed in a detectable form in the nodes before treatment, and the number of lymph follicles per node remained virtually unchanged. At higher doses, the draining lymph nodes not only developed germinal centers in the pre-existing primary follicles, but also produced new primary follicles which in turn developed germinal centers. "Bare germinal centers" were not observed in the draining nodes at any stage after the injection of LPS. Indeed, we have not observed structures resembling "bare germinal centers" in lymph nodes treated with various antigens. These observations suggest that when germinal centers are stimulated to develop outside existing follicles, their development may be preceded by the formation of new primary follicles at the site.

New primary follicles occurred in the superficial cortex and parenchymal band at some distance from the pre-existing follicles. Sometimes, they arose in close proximity to the follicles. In this case, a thin band of extrafollicular tissue containing highendothelial venules (Gowans and Knight, 1964; Bélisle and SaInTe-Marie, 1981) was usually found between the newly developed follicles and pre-existing ones. On the basis of the present findings, it may be concluded that most of the new primary follicles are "de novo" formed at the site with no relation to the pre-existing follicles. Since many of the new primary follicles develop germinal centers in their medullary pole rather soon after their formation, the formation of the follicles appears to be accompanied by the acquisition of a capacity to develop germinal centers, possibly due to the development of follicular stroma with dendritic cells (Williams and Nossal, 1966; Nossal and Ada, 1971; Hoefsmit, 1975; Chen et al., 1978; Hoefsmit et al., 1982). However, the precise mechanism underlying the formation of new lymph follicles still remains unclear.

New lymph follicles frequently occurred in the parenchymal band. This band is thought to represent a peripheral extension of the superficial cortex (SAINTE-MARIE et al., 1982). Under normal conditions, however, the parenchymal band is similar in morphological appearance to the medullary cord. If the plasma cells increase in number as was seen in LPS-treated lymph nodes, they populate the parenchymal band as well as the medullary cord. Thus, the parenchymal band in the mouse popliteal node has dual characters of the superficial cortex and the medullary cord.

The present observations suggest that the development of a new secondary follicle outside a pre-existing follicle is a two-step phenomenon: the first step is the formation of a new primary follicle and the second, that of a germinal center in the newly formed primary follicle. Germinal center development in primary follicles has been regarded as a response to antigens (Pernis et al., 1963; Nossal et al., 1964; Yoffey and Courtice, 1970; Nossal and AdA, 1971) which requires the presence of T lymphocytes (GuTMAN and Weissman, 1972; Weissman et al., 1976). However, is this principle applicable to the formation of new lymph follicles? The present results suggest that antigenic substances, which can induce germinal center development, cannot always stimulate the development of new primary follicles. The lymph follicle formation may be a response to a certain type of antigens, and the formation of new lymph follicles may not necessarily require the presence of $T$ lymphocytes. This is suggested by the present finding that PHA, a polyclonal $\mathrm{T}$ cell activator, failed to produce new lymph follicles in the lymph node, and also by the finding that LPS can induce the formation of new lymph 
follicles in the lymph node of athymic $(\mathrm{Nu} / \mathrm{Nu})$ mice (manuscript in preparation).

The present study shows that LPS can stimulate the formation of new lymph follicles and germinal centers in draining lymph nodes. LPS is a thymus-independent antigen and a polyclonal B cell activator (Coutinho and Möller, 1973; Coutinho et al., 1974; Moatamed et al., 1975), and also an adjuvant (MerRit t and Johnson, 1963; CHILlER et al., 1973). The question of whether any of these known properties of LPS are related to the formation of new lymph follicles in the lymph node awaits further elucidation.

Acknowledgments. We thank Miss Sachiko TAKagi and Mr. Akio Ito for skilled technical assistance.

\section{REFERENCES}

Bélisle, C. and G. Sainte-Marie : Tridimensional study of the deep cortex of the rat lymph node. III. Morphology of the deep cortex units. Anat. Rec. 199: 213-226 (1981).

Bloom, W.: Lymphatic tissue; lymphatic organs. In: (ed. by) H. Downey: Handbook of hematology. Paul B. Hoeber Inc., New York, 1938 (p. 1427-1467).

Byrd, W. J., W. H. Finley, S. C. Finley and S. McClure: Antigenic properties of mitogenic factors in phytohaemagglutinin. Lancet 2: 420-421 (1964).

Chen, L. L., J. C. Adams and R. M. Steinman: Anatomy of germinal centers in mouse spleen, with special reference to "follicular dendritic cells." J. Cell Biol. 77: 148-164 (1978).

Chiller, J. M., B. J. Skidmore, D. C. Morrison and W. O. Weigle: Relationship of the structure of bacterial lipopolysaccharides to its function in mitogenesis and adjuvanticity. Proc. Nat. Acad. Sci. USA 70: 2129-2133 (1973).

Conway, E. A.: Cyclic changes in lymphatic nodules. Anat. Rec. 69: 487-513 (1937).

Coutinho, A. and G. Möller: B cell mitogenic properties of thymus-independent antigens. Nature New Biol. 245: 12-14 (1973).

Coutinho, A., E. Gronowicz, W. W. Bullock and G. Möller: Mechanism of thymus-independent immunocyte triggering. Mitogenic activity of $\mathrm{B}$ cells results in specific immune responses. J. exp. Med. 139: 74-92 (1974).

Gowans, J. L. and E. J. Knight: The route of circulation of lymphocytes in the rat. Proc. Roy. Soc. 159B: 257-282 (1964).

Gutman, G. A. and I. L. Weissman : Lymphoid tissue architecture. Experimental analysis of the origin and distribution of T-cells and B-cells. Immunology 23: 465-479 (1972).

Hoefsmit, E. C. M.: Mononuclear phagocytes, reticulum cells, and dendritic cells in lymphoid tissues. In: (ed. by) R. Van Furth: Mononuclear phagocytes in immunity, infection, and pathology. Blackwell, Oxford-London-Edinburgh-Melbourne, 1975 (p. 129-146).

Hoefsmit, E. C. M., A. M. Duijvestijn and E. W. A. Kamperdijk: Relation between Langerhans cells, veiled cells, and interdigitating cells. Immunobiol. 161: 255-265 (1982).

Hoshi, H., K. Kamiya and E. Endo: Cortical structure of the lymph node. I. Effect of blockage of the afferent lymph flow to mouse popliteal nodes for protracted period. J. Anat. 133: 593606 (1981).

Klaus, G. G. B., J. H. Humphrey, A. Kunkl and D. W. Dongworth: The follicular dendritic cell: Its role in antigen presentation in the generation of immunological memory. Immunol. Rev. 53: 3-28 (1980).

Marshall, W. H. and S. Melman : Antibody production in sheep and man against the mitogenic principle of the bean extract 'phytohaemagglutinin.' Clin. exp. Immunol. 1: 189-193 (1966).

Maximow, A.: Bindegewebe und blutbildende Gewebe. In: Möllendorffs Handbuch der mikroskopischen Anatomie des Menschen. II/1. Springer, Berlin, 1927 (p. 232-584). 
Merritt, K. and A. G. Johnson: Studies on the adjuvant action of bacterial endotoxins on antibody formation. V. The influence of endotoxin and 5-fluoro-2-deoxyuridine on the primary antibody response of the Balb mouse to a purified protein antigen. J. Immunol. 91: 266-272 (1963).

Mitchell, J. and A. Abbot: Ultrastructure of the antigen-retaining reticulum of lymph node follicles as shown by high-resolution autoradiography. Nature 30: 500-502 (1965).

Moatamed, F., M. J. Karnovsky and E. R. Unanue: Early cellular responses to mitogens and adjuvants in the mouse spleen. Lab. Invest. 32: 303-312 (1975).

Nossal, G. J. V. and G. L. Ada: Antigens, lymphoid cells and the immune response. Academic Press, New York-London, 1971.

Nossal, G. J. V., G. L. Ada and C. M. Austin: Antigens in immunity. IV. Cellular localization of ${ }^{125}$ I- and ${ }^{131}$ I-labelled flagella in lymph nodes. Aust. J. exp. Biol. med. Sci. 42: 311-330 (1964).

Nossal, G. J. V., A. Abbot, J. Mitchell and Z. Lummus: Antigen in immunity. XV. Ultrastructural features of antigen capture in primary and secondary lymphoid follicles. J. exp. Med. 127: 277-290 (1968).

Onoé, K.: Changes in histology of the regional lymph nodes and in the proportions of $\mathrm{T}$ and $\mathrm{B}$ cell populations by oxazolone painting or LPS injection in guinea pigs. Acta pathol. jap. 26: 671691 (1976).

Pernis, B., M. W. Cohen and G. J. Thorbecke: Specificity of reaction to antigenic stimulation in lymph nodes of immature rabbits. I. Morphologic changes and globulin production following stimulation with diphtheria toxoid and silica. J. Immunol. 191: 541-552 (1963).

Rudebeck, J.: Experimentelle Untersuchungen über die Sekundärknötchen in den Kniekehlenlymphknoten des Kaninchens bei Staphylokokkeninfektion. Virchows Arch. Pathol. Anat. 284: 504-517 (1932).

Sainte-Marie, G., F. S. Peng and C. Bélisle: Overall architecture and pattern of lymph flow in the rat lymph node. Amer. J. Anat. 164: 275-309 (1982).

Sainte-Marie, G. and Y. M. Sin : The lymph node: Structures and possible function during the immune response. In: (ed. by) A. S. Gordon: Regulation of hematopoiesis. Vol. 2. Appleton-CenturyCrafts, New York, 1970 (p. 1339-1382).

Sjövall, A. and H. Sjövall : Experimentelle Studien über die Sekundärknötchen in den Kniekehlenlymphknoten des Kaninchens bei Bacillus phocyaneus-Infektion. Virchows Arch. Pathol. Anat. 278: 258-283 (1930).

Weissman, I. L., G. A. Gutman, S. H. Friedberg and L. Jerabek: Lymphoid tissue architecture. III. Germinal centers, T cells, and thymus-dependent vs thymus-independent antigens. Adv. exp. Med. Biol. 66: 229-237 (1976).

Williams, G. M. and G. J. V. Nossal: Ontogeny of the immune response. I. The development of the follicular antigen-trapping mechanism. J. exp. Med. 124: 47-56 (1966).

Yoffey, J. M. and F. C. Courtice: Lymphatics, lymph and the lymphomyeloid complex. Academic Press, London-New York, 1970 (p. 530).

Yoffey, J. M. and I. A. Olson: The formation of germinal centers in the medulla of lymph nodes. In: (ed. by) H. Cottier, N. Odartchenko, R. Schindler and C. C. Congdon: Germinal centers in immune response. Springer-Verlag, New York, 1967 (p. 40-48).

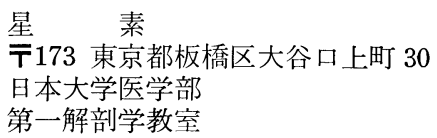

Prof. Hajime Hoshi

Department of Anatomy

Nihon University School of Medicine

Itabashi-ku

Tokyo, 173 Japan 